\title{
APPLICATION OF BEHAVIORAL ECONOMICS INSIGHTS TO INCREASE EFFECTIVENESS OF PUBLIC AWARENESS OF COVID-19
}

DOI: 10.36740/WLek202105114

\author{
Andriana M. Kostenko ${ }^{1}$, Viktoriia 0. Yasenok ${ }^{1}$, Nina D. Svitailo ${ }^{1}$, Mykola S. Nazarov' ${ }^{1}$, Nataliia M. Teslyk1, \\ Olha I. Smiianova' ${ }^{1}$ Ihor V. Huschuk ${ }^{2}$ \\ 'SUMY STATE UNIVERSITY, SUMY, UKRAINE \\ ${ }^{2}$ THE NATIONAL UNIVERSITY OF OSTROH ACADEMY, OSTROH, UKRAINE
}

\begin{abstract}
The aim: To determine the level of public awareness of COVID-19 and information needs, as well as level of public confidence in both official information on COVID-19 and to develop recommendations for communication policy on longer-term awareness in pandemic settings COVID-19, using principles of behavioral economics.

Materials and methods: 4 focus group interviews were conducted in residents of Ukraine, with a total quantity of 48 people aged 16-70 years questioned and an anonymous questionnaire was conducted in 1,700 respondents, representing the adult population aged 18 years and older from all over Ukraine. The representative error of the study with probability of 0.95 does not exceed 4\%. The processing of questionnaires was carried out by SDU Center of Social Researches (SDUCSR) employees, using the 0SA program.

Results: $28.5 \%$ of respondents believe that politicians and media underestimate the danger of the COVID-19 epidemic, while other $28.1 \%$ believe that politicians and media adequately assess its danger. $18.9 \%$ of respondents are sure that the danger is exaggerated. As much as $24.5 \%$ of Ukrainian respondents could not decide on such assessment. The most common sources of information about disease/treatment are Internet and social media. Traditional media and relatives/acquaints who endured the COVID-19 also gain population 's confidence. A family doctor is the least popular source of information. $42.1 \%$ of respondents do not trust official information on the number of infected people and severity of the disease, and another $40 \%$ are not sure whether they should trust or not. Only $17.9 \%$ of respondents trust official information.

Conclusions: Within informing the society about public health in conditions of a COVID-19 pandemic it is better to provide communication strategy for various target audiences: for youth which is inclined to underestimate threats of epidemic and obtains information on social networks; for people of a retirement age (as risk group) who lack information because they use only traditional media (mainly TV); for women who need psychological support to decrease in level of stress in the family more often and also to overcome the negative post-stressful situations (connected with the death of the family/relatives); for men who are inclined to neglect their own health, etc.; for the people who have endured COVID-19 to prevent possible reinfection in them.
\end{abstract}

KEY WORDS: COVID-19, awareness, behavioral economics

Wiad Lek. 2021;74(5):1125-1129

\section{INTRODUCTION}

The outbreak of 2019 coronavirus disease (COVID-19) has become a public health emergency of international concern. The number of COVID-infected individuals and related deaths continues to rise rapidly. COVID-19 is a serious threat to global health and the world economy and has caused widespread concern around the world. In the absence of approved treatments for and vaccines against COVID-19, preventive strategies and hygiene behaviors such as social distancing and stay-at-home policies, avoiding touching the face, and repeated hand washing are effective options in the fight against COVID-19 [1,2]. During this pandemic, encouraging people to adopt and sustain preventive behaviors is a central focus of public health policies that seek to mitigate the spread of COVID-19.

The background of studying the factors for the formation of the motives for compliance/non-compliance with quarantine is also defined by the need recognized by specialists for the long-term application of such restrictions. Today it is already obvious that even the development of a vaccine and mass vaccination are unlikely able to quickly and to- tally overcome the pandemic and bring the situation back to the "pre-COVID" level. In such circumstances, special attention is to be paid to the processes of forming the motives for the behavior of the population in their relation to the recognition of the scale of the threat both to themselves and to immediate circle, which significantly affects the readiness to fulfill the requirements of quarantine.

Behavioral economics has recently received a great deal of attention in public policy making [3]. This field of economics uses insights from the fields of psychology, neuroscience, and cognitive sciences to explain how human behavior deviates from the rational choice theory, when and why people's short-term decisions sometimes undermine their long-term interests. The focus of this field is on better predicting and understanding people's behaviors and choices to help formulate more effective public policies $[4,5]$. It identifies biases in the decision-making process and uses them as entry points for interventions to address particular behaviors.

Behavioral Economics is to understand the environments where decisions are developed and to build proposals to 
optimize them. Although it follows the tradition of the free choice as a deliberative exercise. It is sought that, with small pushes, or the so called "Nudge" (Thaler \& Sunstein, 2008), the individuals choose with help, but without restricting or limiting the options.

Behavioral economics has shed new light on a range of risky and preventive health behaviors [6]. It also has considerable potential for providing a valuable perspective to better understand and explain COVID-19-related behaviors. While multiple biases are identified in the field of behavioral economics, in this paper we focus on six that tend to be particularly relevant to COVID-19-related behaviors: present bias, status quo bias, framing effect, optimism bias, affect heuristic, and herding behavior. It may provide useful insights into public health policies designed to reduce the spread of COVID-19 and may be helpful in developing and implementing interventions.

\section{THE AIM}

To determine the level of public awareness of COVID-19 and information needs, as well as level of public confidence in both official information on COVID-19 and health system as a whole. To develop recommendations for communication policy on longer-term awareness in pandemic settings COVID-19, using principles of behavioural economics.

\section{MATERIALS AND METHODS}

Qualitative and quantitative strategies were used during the analysis. The study was carried out in two stages. Field data collection took place from November 30 to December 18, 2020 , that is, until the New Year and lockdown. The purpose of the first phase was to identify the most common reasons for compliance/non-compliance with quarantine restrictions; identify possible emotions, responses and patterns of population behavior to proposed quarantine measures and restrictions. To achieve this, 4 focus group interviews were conducted in residents of Ukraine, with a total quantity of 48 people aged 16-70 years questioned. Data collection was carried out in on-line form, using the Google-Meet platform, (the in-depth collective interview method (focus group method)) with video recording of participants' answers to questions asked by the focus group moderator, including possibility to hear reactions to replicas of other participants. The purpose of the second stage was to find out factors of compliance/non-compliance with quarantine restrictions by the population for further development of recommendations about formation of communication policy to change of behavior of people in longer term prospective in the conditions of Covid-19 pandemic.

Therefore, an anonymous questionnaire was conducted in 1,700 respondents, representing the adult population aged 18 years and older from all over Ukraine, excluding those living in a territory that is temporarily not controlled by the Ukrainian authorities - the Autonomous Republic of Crimea, certain areas and districts of Donetsk and Lugansk regions. The representative error of the study with probability of 0.95 does not exceed $4 \%$. As a toolkit, a specially developed questionnaire form was used. It was formed, taking into account the results of a focus study conducted at the previous stage. The processing of questionnaires was carried out by SDU Center of Social Researches (SDUCSR) employees, using the OSA program.

The study was approved by the ethics committee of the Sumy State University, Sumy, Ukraine which determined that the general ethical rules of humane treatment of patients were observed when working with patients in accordance with the requirements of the Tokyo Declaration of the World Medical Association and the International Recommendations of the Helsinki Declaration of Human Rights.

\section{RESULTS}

The population divisively accepts assessment of the COVID-19 epidemic from doctors, politicians and media. $28.5 \%$ of respondents believe that politicians and media underestimate the danger of the COVID-19 epidemic, while other $28.1 \%$ believe that politicians and media adequately assess its danger. $18.9 \%$ of respondents are sure that the danger is exaggerated. As much as $24.5 \%$ of Ukrainian respondents could not decide on such assessment.

Among the respondent the older generation showed belief that the danger of the epidemic is underestimated, while youth considers it as exaggerated. In particular, respondents over 50 y.o. believe that politicians and media underestimate the danger of the epidemic (35.7\%), and young people aged 18-29 believe that the danger is exaggerated $(23.9 \%)$.

The most common sources of information about disease/ treatment are Internet and social media. Traditional media and relatives/acquaints who endured the COVID-19 also gain population's confidence. A family doctor is the least popular source of information to address according to the answers.

$57.7 \%$ of respondents are receiving information about disease/treatment through the Internet and social networks. Another $45.6 \%$ prefer traditional media (television/radio/ newspapers). $37.1 \%$ of respondents trust relatives and acquaints who endured the disease. $33 \%$ apply to the official websites (e.g. Ministry of Health site). Only $17.7 \%$ of respondents apply to a family doctor for information (Figure 1).

As for professional information, the respondents show trust for informal communication channels, and especially for experts who use blogs, social networks, and present available and structured information to submit.

Respondents, who have already endured COVID-19, are more likely to receive information from a family doctor $(25.1 \%)$; official sites (Ministry of Health) (34.5\%), doctors' blogs (17.8\%) and acquaints who have already endured the disease (40.7\%).

Respondents who were not ill or are not sure that they could/can be ill at present moment are more often to receive information from traditional media ( $47 \%$ each), Internet sources and social networks (61.1\%). 

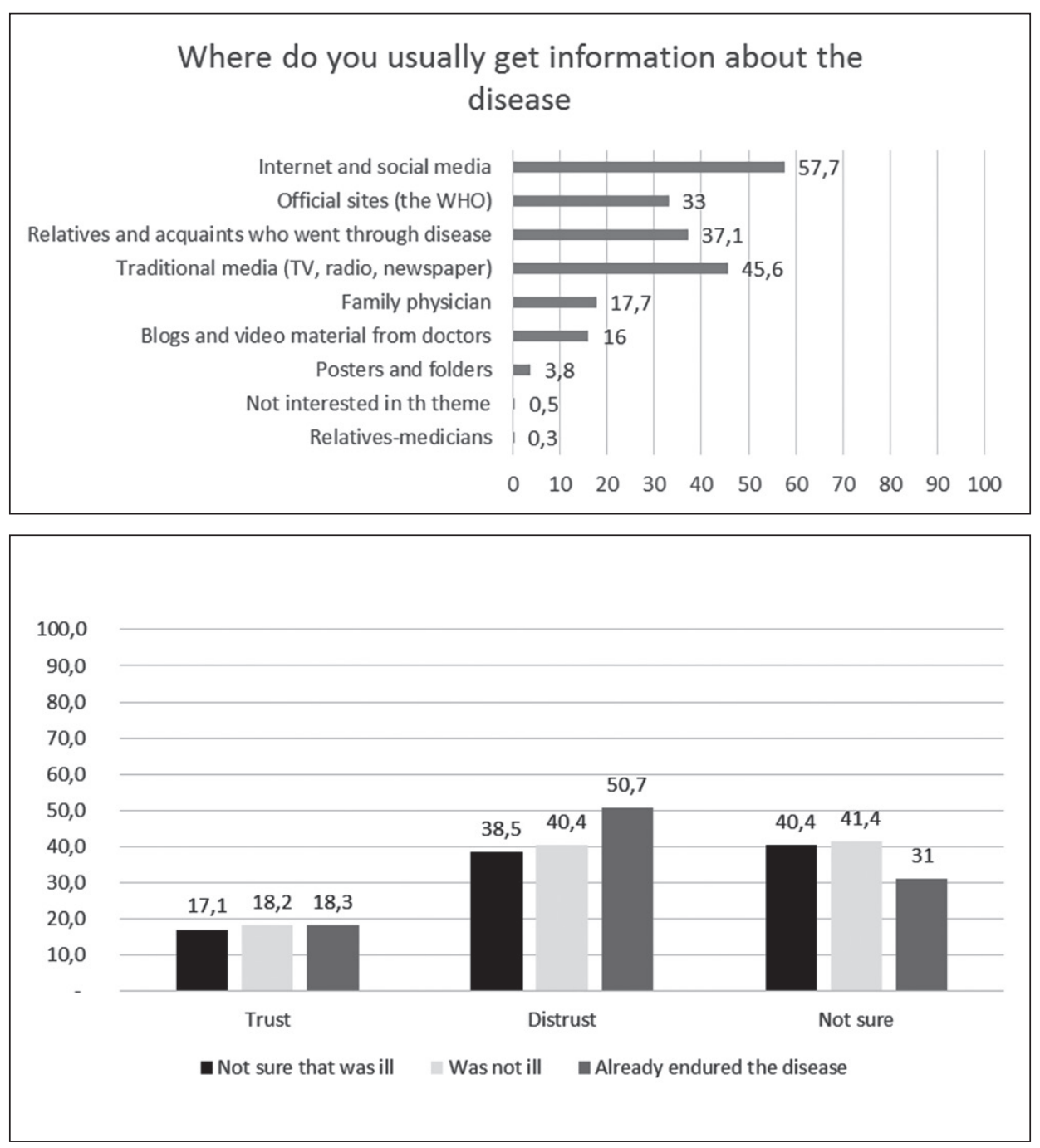

Fig. 1. Where do you usually get information about the disease? (from the questionnaire)
Fig. 2. What is your attitude to the official information on number of ill and severity of the disease? (from the questionnaire)
Women are more likely to receive information about illness/treatment from relatives or acquaints who endured the disease ( $40.1 \%$ of women versus $32 \%$ of men).

Young people are more likely to get information from social networks and official sites, the population aged 30 39 receives it from family doctor, and the population over 50 - from relatives and acquaints who have endured the disease as well as from traditional media and family doctor.

Most respondents claim that there is enough information on the COVID-19, but it is complicated. According to the answers for question about lack or adequacy of COVID-19 information, $38.6 \%$ of respondents believe that there is a lot of information, although they find it contradictory and inaccurate. Another $36.1 \%$ claim that information is enough and is not difficult to find.

Only $19.1 \%$ of respondents consider that more information is needed, especially from official sources and with clearer instructions. Only $6.2 \%$ are not interested in the specified information and do not believe that someone may know something more reliable on the subject.

It is worth mentioning that men and women interviewed, express various assessments regarding the adequacy and quality of information. Thus, men often claim that information is enough and is easy to find (38.1\% against $34.8 \%$ of women). In addition, there are men who often note (7.1 $\%$ versus $5.7 \%$ of women) that they are not interested and do not believe that someone knows something reliable on the subject.

At the same time, women have shown great demand for the quality and reliability of information. So, they are more often ( $20 \%$ versus $17.6 \%$ of men) to note that more clearer information from official source is needed, and are also dissatisfied with the fact that there is a lot of information, but it is contradictory and inaccurate $(39.5 \%$ of women versus $37.2 \%$ of men).

Respondents, who endured the disease are sure that they have enough information and it is easy to find it (38.5\%). Interviewees, who did not go through the COVID-19 or are not sure if they are ill at present, claim that there is much information, but it is contradictory and unreliable.

The older are the respondents, the more they inform about the need for official information with clear instructions.

Even though a large number of respondents claim about sufficient quantity of information about COVID-19, there is still a need in it present. Thus, the population lacks information about medicines and remedies that will provide visible protection (39.6\%); mild forms of treatment (32.8\%); 
rehabilitation types (32.3\%); treatment of complex form $(29.2 \%)$; disease protection and prevention $(28.1 \%)$ and the algorithm for seeking a medical care if fallen ill ( $28 \%)$.

Respondents who endured the COVID-19, are lack of information on rehabilitation ( $38 \%$ ), treatment of a complex form (32.6\%) and on receiving medical care with an absence of a concluded agreement with family doctor $(18.9 \%)$. Respondents who were not ill need information about protection from the disease and prevention (30\%), treatment of the mild form (33.7\%) and the algorithm for seeking medical care $(29 \%)$. Interviewees who are unsure whether they are possibly ill at present or not, need information about symptoms of the disease (22.4\%); drugs and remedies that will provide real protection $(44.7 \%)$, patients around and their real number (21.8\%).

The population does not trust the official information on the number of infected and the severity of the disease.

$42.1 \%$ of respondents do not trust official information on the number of infected people and severity of the disease, and another $40 \%$ are not sure whether they should trust or not. Only $17.9 \%$ of respondents trust official information.

At the same time, the study shows that men are more likely to trust official information (19.7\% versus $16.8 \%$ of women). However, women are more likely to indicate that they are not sure ( $41.8 \%$ versus $37 \%$ of men).

Interviewees, who endured the disease are more likely to express distrust to an official information (50.7 \% among those who were ill vs $40.4 \%$ - who were not ill and versus $38.5 \%$ that are not sure if they were ill or not) (Figure 2).

The population aged 40-49 years often demonstrates that they do not trust official information (47.7\%). Respondents aged 18-29 also often note that they do not know whether they should relate to the official information ( $47.8 \%)$. The population over the age of 50 tends to trust official information about the number of infected and severity of the disease.

\section{DISCUSSION}

Behavioral Economics should encourage governments to eliminate the presence of behavioral biases in humans, so as to reduce the impact of the pandemic. The analysis of factors which cause certain behavior in people during the pandemic, particularly concerning the level of knowledge about COVID-19 and level of trust and compliance among the population to official information on COVID-19 and to a medical system in general, allows to create recommendations to form the communication policy to change population behavior in longer term prospect in the conditions of COVID-19 pandemic. They include:

1. Addressing availability bias and retrospective bias by communicating facts, action plans and expected role of citizens in a clear and timely manner. The government must provide information on an ongoing basis and disprove fake news;

2. Making it easier for citizens to find information about COVID-19 through official sources, and provide hotlines during the pandemic;

3. Building a correct mental model for citizens, giving more publicity on government websites to the COVID-19 recovery cases rather than to the number of infected cases and victims, without downplaying the seriousness of the situation;

4. Showing videos of trusted public figures, who encourage self-care, express empathy and solidarity with patients, appreciate frontline health workers and destroy myths related to the virus;

5. Providing curricula (extracurricular hours) for the development of safe behaviour and self-care skills for students and pupils;

6. Establishing a system to inform parents of safe behaviour and skills to take care about themselves and children;

7. Continually demonstrating of the need for precautionary measures such as hand washing and encouraging people to stay home;

8. Making it mandatory to place soap and disinfectant dispensers by the entrance doors of offices, supermarkets, shopping malls and public buildings. These efforts towards effective risk communication by public authorities will help build the credibility of government measures, provide people with early guidance and allow uncertainty to be normalized. The communication strategy is key and it is best to report the seriousness of the situation with transparency and clarity, but without creating any kind of scaremongering. Behavioral Economics indicates that the response of citizens to the advice of the authorities on preventive measures is fundamental to get out of this crisis.

\section{CONCLUSIONS}

Thus, within informing the society about public health in conditions of a COVID-19 pandemic it is better to provide communication strategy for various target audiences: for youth which is inclined to underestimate threats of epidemic and obtains information on social networks; for people of a retirement age (as risk group) who lack information because they use only traditional media (mainly TV); for women who need psychological support to decrease in level of stress in the family more often and also to overcome the negative post-stressful situations (connected with the death of the family/relatives); for men who are inclined to neglect their own health, etc.; for the people who have endured COVID-19 to prevent possible reinfection in them.

Sending simple and clear messages is extremely important to create the necessary public response and reduce economic costs to health and the economy. It is necessary to report clearly and simply, without causing panic or social anxiety. A person is not psychologically ready to adapt to rapidly changing information, and therefore he must be aware that he or she will have to review information about the disease, its spread and various ways to combat it, so he must be prepared to make changes. Unlike politicians, scientists and health professionals are among the most trusted professions among citizens. That is why it is important to centralize epidemiological information, and to some extent decisions, in health authorities, as they are the ones who 
may have the greatest epidemiological knowledge. The existence of emergency committees made up of scientific experts is necessary, not only to decide, but also to inform. Political confrontation should be avoided and the greatest possible coordination between institutions should be sought. To build trust, governing institutions should not take advantage of the situation to boast about good measures, nor should opposition criticize bad management.

The media should transmit realistic information without taking advantage of the sensationalist vein that can lead them to attract attention. The focus should not be exclusively on the numbers of people affected and killed, but on what can and should be done to prevent the pandemic.

Citizens must not create panic or spread misinformation, especially with the current degree of

connectivity allowed by social networks. Human beings are incapable of processing information in situations of stress and panic. Therefore, the messages conveyed must be simple and clear. Thus, massive purchases have been seen, which, although they can momentarily calm the human being, can collectively contribute to create shortages of health products or basic needs. Actions must be taken to avoid promoting misconduct among citizens that would further aggravate the situation.

\section{REFERENCES}

1. Chen Y., Liu Q., Guo D. Emerging coronaviruses: genome structure, replication, and pathogenesis. J Med Virol. 2020;92(4):418-23.

2. Wilder-Smith A., Freedman D. Isolation, quarantine, social distancing and community containment: pivotal role for old-style public health measures in the novel coronavirus (2019-nCoV) outbreak. J Travel Med. 2020;27(2).

3. Congdon W.J., Shankar M. The role of behavioral economics in evidencebased policymaking. Ann Am Acad Pol Soc Sc. 2018;678(1):81-92.

4. Thaler R.H., Sunstein C.R. Nudge: improving decisions about health, wealth and happiness. New Haven: Yale University Press; 2008.

5. Thaler R.H. Behavioral economics: past, present, and future. Am Econ Rev. 2016;106(7):1577-600.

6. Bickel W.K., Moody L., Higgins S.T. Some current dimensions of the behavioral economics of health-related behavior change. Prev Med. 2016;92:16-23.
The study was conducted by the Center for Social and Humanitarian Aspects of Regional Studies, Sumy State University, during November-December 2020 as part of the Initiative for the Development of Analytical Centers in Ukraine, which is being carried out by the Revival International Fund in partnership with the Open Society Initiative for Europe (OSIFE) with financial support from the Swedish Embassy in Ukraine.

\section{ORCID and contributionship:}

Andriana M. Kostenko: 0000-0002-8970-4244 ${ }^{A, E}$

Viktoriia O. Yasenok: 0000-0003-3250-2112

Nina D. Svitailo: 0000-0002-4944-1064 ${ }^{\mathrm{C}}$

Olha I. Smiianova: 0000-0001-5823-924X ${ }^{B, E}$

Mykola S. Nazarov: 0000-0002-4504-7908 B, C, E

Nataliia M. Teslyk: 0000-0002-1564-8323 ${ }^{C}$

Ihor V. Hushchuk: 0000-0002-8075-9388 D, F

\section{Conflict of interest:}

The Author declare no conflict of interest

\section{CORRESPONDING AUTHOR Viktoriia 0. Yasenok \\ Sumy State University \\ 2 Rimsky-Korsakov St., 40000 Sumy, Ukraine \\ tel: +380669027860 \\ e-mail:v.kurganskaya@med.sumdu.edu.ua}

Received: 05.12 .2020

Accepted: 29.03 .2021

A - Work concept and design, B - Data collection and analysis, C - Responsibility for statistical analysis, D-Writing the article, $\mathbf{E}$-Critical review, $\mathbf{F}$ - Final approval of the article 